\title{
PERANCANGAN DAN IMPLEMENTASI SOUND LEVEL METER (SLM) DALAM SKALA LABORATORIUM SEBAGAI ALAT UKUR INTENSITAS BUNYI
}

\author{
${ }^{1)}$ Jamaludin, ${ }^{1\}}$ Suriyanto, ${ }^{1)}$ David Adiansyah, ${ }^{1)}$ M Sholachuddin A, ${ }^{1)}$ Imam Sucahyo \\ ${ }^{1)}$ Prodi Fisika Jurusan Fisika FMIPA Universitas Negeri Surabaya \\ ${ }^{*}$ Email: didinjamal861@gmail.com
}

\begin{abstract}
Laboratory based research is the implementation of Wave Mechanics ( GM ). In this physical peristtiwa will be examined on Wave Mechanics in measuring the intensity of sound . In order to determine the relevant SLM using a condenser mic as well as determine the level of noise in the sound of different frequencies in the laboratory scale. Tests carried out under conditions of sound intensity soundproof space and sound intensity comparison with SLM industrial design. In this study also compares the design of the SLM SLM Nor-118. So that the data obtained is the result of data collection we did the design of the SLM SLM Nor- 118 can be said to be relevant, but there is a difference is a difference of $\pm 5.0 \%$. And at a certain frequency when he would decline due to several internal and external factors. The conclusions drawn are in any retrieval of data must be in the soundproof room so that when the data collection is no factor that affects both external and internal.
\end{abstract}

Keywords : Sound Level Meter, Wave Mechanics

\begin{abstract}
Abstrak
Penelitian yang berbasis laboratorium merupakan implementasi dari Gelombang Mekanik (GM). Pada peristtiwa fisis ini akan diteliti tentang Gelombang Mekanik dalam mengukur Intensitas Bunyi. Guna untuk mengetahui SLM yang relevan menggunakan mic condenser serta menentukan kebisingan bunyi dalam tingkat frekuensi yang berbeda dalam skala Laboratorium. Pengujian intensitas bunyi dilakukan dalam kondisi ruang yang kedap suara serta perbandingan intensitas bunyi dengan SLM rancangan industri. Dalam penelitian ini juga membandingkan antara SLM Rancangan dengan SLM Nor-118. Sehingga data yang diperoleh adalah hasil dari pengambilan data yang kami lakukan antara SLM Rancangan dengan SLM Nor-118 bisa dikatakan relevan namun ada perbedaan selisih sebesar $\pm 5.0 \%$. Dan pada saat frekuensi tertentu dia akan menurun yang disebabkan oleh beberapa faktor internal dan eksternal. Kesimpulan yang diambil adalah dalam setiap pengambilan data harus dalam kondisi ruang yang kedap suara sehingga ketika dalam pengambilan data tidak ada faktor yang mempengaruhi baik eksternal maupun internal.

Kata Kunci : Sound Level Meter, Gelombang Mekanik
\end{abstract}




\section{PENDAHULUAN}

Dalam penerapan teknologi elektronika dalam kehidupan sehari-hari telah membawa manusia pada peradaban yang lebih tinggi dan menjadikannya sebagai tolak ukur terhadap kemajuan suatu negara. Teknologi tepat guna banyak diciptakan untuk membantu pekerjaan manusia sehari-hari terutama untuk masalah-masalah yang muncul dalam kehidupan sekarang. Permasalahan seharihari akan datang setiap waktu salah satu diantaranya mengenai masalah transmisi bunyi. Permasalahan yang tidak lepas dari bagian konsep dasar fisika tersebut, merupakan perambatan gelombang mekanik dalam suatu medium. Pada prinsipnya, gelombang adalah energi yang merambat dalam ruang, leh karena itu, akan sangat menarik untuk mengetahui apa yang terjadi bila gelombang mekanik (misalnya bunyi) merambat dan tiba pada suatu permukaan.

Penelitian ini difokuskan pada pengukuran kebisingan, mengingat dampak negative dari kebisingan dalam berbagai bentuk, pengendalian kebisingan dapat dilakukan jika sudah diketahui atas kebisingan suatu area dan pengukuran atas kebisingan dapat dilakukan dengan menggunakan Sound Level Meter (SLM).

Penelitian ini merupakan studi tentang transmisi gelombang bnyi pada alat yang mendeteksi kebisingan suara yaitu Sound Level Meter (SLM). Perancangan ini dibuat dalam skala laboratorium dengan ambang frekuensi suara yang mampu di dengar oleh manusia secara normal yaitu antara $20 \mathrm{~Hz}$ sampai $20 \mathrm{KHz}$. Selain itu peneliti juga akan membandingkan SLM yang dirancang dengan SLM Nor-118. Agar dapat diketahui sberapa besar taraf ketelitian yang diperoleh dari nilai intensitas bunyi pada alat yang sudah buat dengan hasil buatan indusri.

Berdasarkan uraian diatas sebelumnya maka dalam rumusan masalah dalam penelitian ini adalah bagaimana merancang Sound Level Meter (SLM) dalam skala laboratorium dan bagaimana sensifitas mic condenser dalam menentukan tingkat kebisingan dengan menentukan tingkat kebisingan bunyi dengan tingkat kondisi frekuensi yang berbeda.

Bunyi terjadi karena adanya benda yang bergetar yang dapat menimbulkan gesekan dengan zat disekitarnya. Getaran objek atau udara yang menyentuh partikel zat yang ada didekatnya yaitu berupa gas, cairan, ataupun padatan, tergantung letak obyek yang bergetar. Keras lemahnya bunyi sangat dipengaruhi oleh sensasi yang ditimbulkan pada pendengaran seseorang. Keras buyi bertambah jika intensitas meningat, tetapi pertambahan ini tdak terjadi secara linier. Semakin besar amplitudo maka keras bunyi yang dihasilkan akan semakin besar. Hal ini dengan sesuai dengan energi getaran :

$$
\begin{aligned}
& \mathrm{E}=1 / 2 \mathrm{kA}^{2} \ldots \ldots(1.1) \\
& \text { Dimana }: \\
& \mathrm{E}=\text { Energi getaran } \\
& \mathrm{K}=\text { konstanta pegas } \\
& \mathrm{A}=\text { Ampiltudo }
\end{aligned}
$$

Energi getaran bergantung pada amiltudo dan amplitude juga bergantung frekuensi yang diberikan. Semakin besar energy getaran maka semakin kuat kesan pendengaran yang tertangkap oleh telinga.

Intensitas adalah jumlah energi bunyi tiap detiknya menembus tegak lurus bidang seluas satuan luas. Karena luasnya daerah bunyi yang dapat diterima telinga manusia, dan penggunaan skala logaritma akan mempermudah pembacaan harga intensitas bunyi. Hubungan intensitas (I) dengan tingkat intensitas suara dinyatakan dengan :

$$
\begin{aligned}
& \mathrm{L}=10 \log \mathrm{I} / \mathrm{I}_{0} \quad \ldots \ldots(1.2) \\
& \text { Dimana: } \\
& \mathrm{L}=\text { tingkat intensitas bunyi (sound } \\
& \text { pressure level) dB } \\
& \mathrm{I}=\text { intensitas suara }\left(\text { watt } / \mathrm{m}^{2}\right. \text { ) }
\end{aligned}
$$


ISSN: 2087-9946

$\mathrm{I}_{0}=$ intensitas referensi

Pada penguuran intensitas bunyi dengan menggunakan dikenal dengan istilah sound pressure level (SPL), yaitu nilai yang menunjukkan prubahan pada tekanan didalam udara karena ada perambatan gelombang bunyi.[7]

Microphone condenser adalah salah satu jenis dari mikrofon yang tidak memunyai sumber muatan sendiri, sehingga memerlukan suatu pencatu daya dari luar mikrofon tersebut akan merespon atau bekerja jika ada sinyal tekanan bunyi yang masuk dan tepat mengenai space antara membran tipis dari logam dan plat yang tidak berubah. Kelebihan dari mik condenser ini adalah merespon bunyi dengan baik sedangkan kerugiannya adalah dalam penggunaan berhati-hatilah, karena kondensor yang dipakek data meletus dan pecah jika ada benturan atau tegangan yang keras dan kelbihan voltase. Mic Condenser memerlukan power dari luar atau suplai eksternal. Sinyal yang dihasilkan oleh tipe ini lebih kuat dibandingkan dengan tipe yang lainnya. Condenser juga lebih sensitive dan responsive sehingga dapat digunakan untuk mengambil perbedaan suara. Namun tipe mic condenser ini tidak cocok pada volume tinggi karena sensitifitasnya membuat mudah terdistorsi.[10]

\section{METODE PENELITIAN}

Penelitian tentang perancangan dan implementasi sebagai alat ukur dari intensitas bunyi yang berbasis eksperimen dalam laboratorium. Data yang digunakan dalam penelitian ini merupakan data sekunder, yaitu hasil yang didapatkan dalam praktikum murni dari program.
Tahapan pengambilan data adalah sebagai berikut:

1) Tahap persiapan, yaitu mengidentifikasi masalah yang akan diteliti. Dan diskusi dalam pelaksanaan penelitian sehingga penelitian ini dapat dilakukan berdasarkan teori-teori perancangan;

2) Merancang system otomatisasi alat berabasis mikrokontroller untuk menentukan intensitas bunyi;

3) Pembuatan program pendukung mikrokontroller dengan menggunakan bahasa $\mathrm{C}$ untu memproses dan menampilkan hasil data yang diperoleh;

4) Tahap pengujian yang dilakukan adalah mengecek system bahwasanya alat sudah siap dilakukan kalibrasi dan pengambilan data;

5) Melakukan pengambilan data dan mengati, mencatat respon sensor mic condenser dengan cara memberikan objek suara didean mic condenser tersebut, kemudian terdeteksi oleh lampu indikator led menyala atau tidak;

6) Memproses data dan menganalisa data yang telah diperoleh dalam eksprimen.

Hasil yang diperoleh dari data eksperimen kemudian dianalisis dan dibuat tabel dan grafik sehingga pada saat membaca data akan lebih mudah dengan melihat grafik yang dihasilkan dari data tersebut.

\section{HASIL DAN PEMBAHASAN}

Dalam pengambilan data yang telah dilakukan pada suatu ruangan, dimana ruangan tersebut menguji alat yang telah kami buat dan siap untuk di ujicobakan. Hasil yang telah diperoleh adalah sebagai berikut 
Tabel 1. Hasil pengambilan data

\begin{tabular}{|c|c|c|c|c|}
\hline \multirow[b]{2}{*}{ No. } & \multirow[b]{2}{*}{$\begin{array}{l}\text { Jarak } \\
\text { (cm) }\end{array}$} & \multirow[b]{2}{*}{$\begin{array}{c}\text { Frekuensi } \\
\text { (Hz) }\end{array}$} & \multicolumn{2}{|c|}{ Intensitas Bunyi (dB) } \\
\hline & & & $\begin{array}{c}\text { SLM } \\
\text { NOR } 118\end{array}$ & $\begin{array}{c}\text { SLM } \\
\text { Rancangan }\end{array}$ \\
\hline 1 & \multirow{10}{*}{10} & 100 & 75.2 & 78.4 \\
\hline 2 & & 200 & 85.4 & 81.7 \\
\hline 3 & & 300 & 90.6 & 84.9 \\
\hline 4 & & 400 & 94.6 & 94.8 \\
\hline 5 & & 500 & 98.5 & 108.2 \\
\hline 6 & & 600 & 101.3 & 109.5 \\
\hline 7 & & 700 & 103.6 & 114.2 \\
\hline 8 & & 800 & 104.1 & 108.6 \\
\hline 9 & & 900 & 102.2 & 109.8 \\
\hline 10 & & 1000 & 105.1 & 114.2 \\
\hline
\end{tabular}

Berdasarkan hasil pengambilan data yang telah dilakukan dan diperoleh data dengan jarak $10 \mathrm{~cm}$, frekuensi yang kita pakai adalah frekuensi mulai dari $100 \mathrm{~Hz}$ sampai $1000 \mathrm{~Hz}$, sehingga data yang diperoleh dari SLM Rancangan dengan SLM Nor 118 buatan pabrik hampir mendekati. Secara teori nilai yang didapatkan dari SLM Rancangan membuktikan pada saat ruangan itu kedap suara maka gelombang bunyi yang diberikan oleh spiker terhadap mic condenser bernilai rendah sehingga mic condenser merespon dengan baik. Pada penggunaan SLM Nor 118 gelombang bunyi yang diberikan oleh spiker terhadap mic condenser SLM Nor 118 merespon dengan baik dan nilai yang ditunjukkan hamir sama dengan SLM Rancangan. Kedua alat tersebut sama-sama merespon gelombang bunyi yang dikeluarkan dari spiker dengan baik sehingga ruangan yang dipakai dikatakan kedap suara.

Dari tabel diatas bisa dijadikan grafik sehingga analisa untuk grafik sebagai berikut :

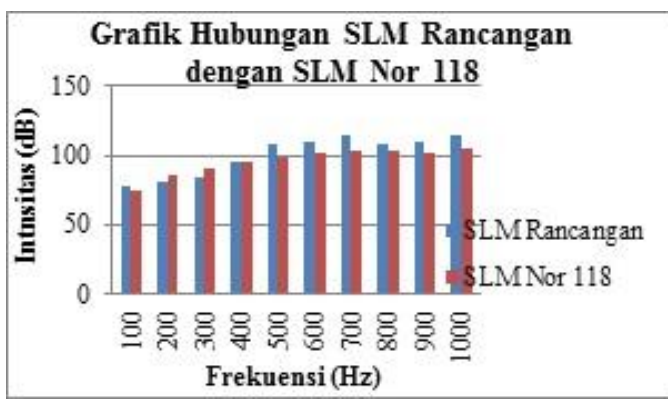

Gambar 1. Grafik hubungan SLM

Rancangan dengan SLM Nor 118

Berdasarkan grafik yang telah dihasilkan dalam eksperimen yang telah dilakukan menerangkan bahwa pada grafik diatas secara umum pengukuran SLM Nor 118 dengan SLM Rancangan berpengaruh terhadap perubahan frekuensi dan jarak juga berpengaruh terhadap intensitas, pada saat pengambilan data mulai dari $100 \mathrm{~Hz}$ sampai $1 \mathrm{KHz}$ melihat dari grafik yang ditunjukkan dari tabel menunjukkan bahwa terjadi naik turun da nada pula yang hasilnya sama namun berbeda selisih. Frekuensi $100 \mathrm{~Hz}$ menunjukkan hasil hamper sama namun beda selisih sebesar $3.2 \%$ dan terendah dari beberapa frekuensi. Pada saat kondisi $500 \mathrm{~Hz}$ sampai $1 \mathrm{KHz}$ mengalami kenaikan pada frekuensi tersebut. Dan pada saat kondisi $400 \mathrm{~Hz}$ menghasilkan intensitas bunyi yang sama antara SLM Rancangan dengan SLM Nor 118 namun beda selisihnya sebesar $0.2 \%$. Dan ketika frekuensi 900 $\mathrm{Hz}$ kondisi dari SLM Nor 118 dan SLM Rancangan mengalami penurunan, dari penurunan tersebut dapat kita analisa bahwa penurunan tersebt disebabkan oleh faktor eksternal (kondisi ruangan masih belum $100 \%$ kedap suara) dan faktor internal (sensor yang kam gunakan masih kurang sensitif). Dari hasil yang telah kami lakukan menerangkan bahwa untuk konsep penelitian kedepannya apakah hal tersebut sudah layak dijadikan alat bantu dalam mengukur tekanan bunyi. 


\section{SIMPULAN DAN SARAN}

Berdasarkan hasil penelitian dan pembahasan, maka dapat dari hasil praktikum yang telah dilakukan sebagai berikut:

1. Perancangan sound level meter telah selesai dan bisa diujicobakan dengan sound level meter buatan pabrik;

2. Dari percobaan eksprimen yang telah dilakukan dengan cara membandingkan SLM Rancangan dengn SLM Nor 118 menemuan hasil yang berbeda disebabkan oleh faktor internal dan eksternal;

3. Nilai yang ditunjukkan oleh SLM Rancangan dengan SLM Nor 118 memiliki perbedaan selisih $\pm 5,0 \%$ dari eksperimen yang kami lakukan;

4. Mic condenser yang kami gunakan sebagai alat ukur untuk mengukur intensitas bunyi merespon dengan baik dalam frekuensi yang berbeda.

Dalam penelitian tentang tentang perancangan sound level meter dan implementasi sebagai alat ukur intensitas bunyi masih dalam tahap pengujian yang dibandingkan dengan sound level meter buatan pabrik sehingga untuk implementasinya masih proses penelitian selanjutnya. Dan pada saat pengambilan data agar melihat kondisi ruangan atau kondisi laboratorium apakah bener-bener kedap suara atau belum, karena sangat pengaruh terhadap respon dari mic condenser. Ruangan atau gedung yang tertutup belum tentu kedap suara, sehingga sangat diperlukan untuk melihat kondisi ruangan yang akan kita paai untuk melakukan eksperimen.

Semoga untuk kedepannya bisa bisa digunakan untuk semuanya dan berguna bagi kita semua.

\section{UCAPAN TERIMA KASIH}

Tim Peneliti menyampaikan terima kasih kepada LPPM UNESA karena telah mendanai penelitian ini, serta dukungan dari teman-teman mohon maaf jika ada kealahan tau kekurangan dalam pembuatan jurnal ini.

\section{DAFTAR PUSTAKA}

${ }^{[1]}$ Alonso Marcelo, Edward J. Finn. 1980. Dasar-dasar Fisika Universitas. (diterjemahkan Dra. Lea Prasetyo dan Ir. Kusnul Hadi). Jakarta : Erlangga

${ }^{[2]}$ Andrianto, Heri. 2008. Pemrograman mikrokontroler AVR Atmega 16. Informatika:Bandung.

${ }^{[3]}$ Eagle J. 1999. Sound System References Manual. New York: JBL Professional.

${ }^{[4]}$ Leo, L,B. 1986. Acoustics. Mc GrawHill Book Company. New York.

${ }^{[5]}$ Prasetio, L. 1985. Akustik Lingkungan (terjemahan dari Doelle, L, L. 1972). Erlangga. Surabaya.

${ }^{[6]}$ Prasetio, L. 2003. Akustik. Hibah Pengajaran. Jurusan Fisika FMIPA, Institut Teknologi Sepuluh November. Surabaya.

${ }^{[7]}$ Plant, Malcolm \& Stuart, Jan. 1985. Pengantar Ilmu Teknik Instrumentasi. Ignatinus hartono, Penerjemah. Jakarta: PT. Gramedia

${ }^{[8]}$ Smith, B.J. 1996. Acoustics and Noise Control. British Library Cataloguing in Publication Data. London

${ }^{[9]}$ Thomas D. Rossing. 1981. The Science of Sound. Addison-Wesley Publishing Company.

${ }^{[10]}$ http://korn-nel.blogspot.com/2010/10/analisiskarakter-suara.html

${ }^{[12]} \underline{\text { http://nimroatul.wordpress.com/2012/05 }}$ /16/akustik/ 